resemble the primary root generally, in their turn producing roothairs and daughter roots, which radiate from them in all directions into new portions of the soil, as shown in this diagram.

I need not do more than point out to you that it would be difficult to conceive of a series of adaptations better calculated to insure that the various parts of the root-system come successively in contact with the whole mass of soil traversed ; and when your eyes follow mine over this diagram, you will agree that matters have become so arranged, so to speak, between the roots and the soil, that every part of the latter is laid under contribution. Notice how this vertical cylinder of earth is first bored through by the primary root, and then traversed in all directions by the root-hairs, in a wave, as it were, passing from above downwards. Next come the lateral roots, burrowing in all directions from the main shaft, and each in turn demanding toll from the cylinder around it by means of its wave of roothairs. Then follow tunnelings along the lengths of each of these rootlets, and on all sides at right angles to them, until every nook and cranny has been investigated by these enterprising rootlets and their prying root-hairs. Quite apart from all else, therefore, the root-system obtains a greater and greater holdfast on the soil by driving its tips in on all sides.

But I must now draw your attention to some matters which throw even more light on our subject. The root-hairs, as they develop successively from above downwards on the primary root, or on the lateral rootlets, come into the closest contact with the particles of soil-contact so close and firm, in fact, that they cannot be torn away without injury. There are experiments to prove that their cellulose walls become actually moulded and gummed on to the solid particles of quartz, slate, and other rocks of which ordinary soils are composed, and this diagram shows how we can lift up a relatively large cylinder of soil adhering to the root-hairs of a young seedling.

Now you are probably aware that the sort of soil in which a healthy plant flourishes contains air-bubbles as well as water in the interstices between the particles, and into which the roothairs become insinuated. Bearing this in mind, you will have no difficulty in understanding from the diagram how the roothairs absorb the aërated water necessary for their well-being. I need simply make the additional remark that each little bag-like root-hair takes up the liquid water through its permeable walls into its interior, in some respects very much as a bladder full of a solution of sugar or salt would absorb water if placed in it.

But this water taken up by the root-hairs and passed on into the rootlets and so on up the stem (a process for which provisions are made which we cannot go into here), is not pure water ; it contains, besides air, certain small proportions of the soluble matters found in all soils. It is, in fact, much like ordinary drinking-water from a well or spring, which always contains some matters in solution. But the roots want certain other minerals, which will not dissolve in pure water to a sufficient extent under ordinary circumstances. Well, the root-hairs, in making use of the oxygen which they, like all other living bodies, require, give off small quantities of acids which aid the solution of these more refractory matters.

And now I have finished-not because the subject is exhausted, but because the time at our disposal is. I hope the object has been attained, and that you fully realise how well worthy of study is a common living root. Not only is it instructive as a simple object of dissection, a subject upon which I have had no time to dwell, but the peculiar properties which stamp it as a living organ themselves afford material for much thought and investigation. When we go further, however, and see how the structure and the functions depend upon one another, some very curious reflections thrust themselves upon us ; and if time had allowed us to look at these matters from the other platforms of view-to see how old errors have gradually been explained away on the part of observers, and how what may be called improved adaptations have arisen in the evolution of the root as an organ-these reflections would have obtained in depth. But we have taken a glimpse at matters still more comprehensive : we have touched upon that important question of the relation of the root to its physical environment, and it is not difficult to see numerous points where the struggle must have been intense before the plastic substance of the root was enabled to meet the requirements necessary before it could become a dweller in the land. The evidence of progress and adaptation to its environment on the part of the root is, in fact, so striking and conclusive, that we might take it as a text for a sermon on evolution were such necessary. I have been strongly tempted to occupy some more time with reference to the interesting phenomena shown by roots which cling to trees and walls, \&c., or which rob other plants of food-materials; and had time allowed, I would have liked to say a few words about some other adaptations, such as those by means of which roots become pulled up taut in the soil. However, these and other matters cannot be even mentioned, and, indeed, each one deserves a lecture to itself.

\section{FOCAL LINES}

WHEN a pencil of light proceeding from a luminous point is incident upon a prism, the rays after refraction do not as a rule diverge from a point, but from two short lines at right angles to each other at some distance apart depending on the angle of incidence of the pencil. These lines are known as the focal lines of the pencil. If the edge of the prism be vertical and the axis of the pencil lie in a horizontal plane, the focal lines are respectively horizontal and vertical. The position of the horizontal line is independent of the angle of incidence of the pencil, its distance from the prism being the same as that of the luminous point, or with the notation of Parkinson's " Optics" (p. 88) -

$$
z_{2}=u \text {. }
$$

The distance from the prism of the vertical focal line is, on the other hand, dependent on the angle of incidence, its position being given by the formula-

$$
v_{1}=\frac{\cos ^{2} \phi^{\prime} \cos ^{2} \psi}{\cos ^{2} \phi \cos ^{2} \psi^{\prime}} \cdot u
$$

The image of an object viewed through the prism will appear between the two focal lines, and will be formed by the circles of least confusion. The two focal lines will coincide in position, and they, and the circles of least confusion, will consequently become points if $\phi=\phi^{\prime}$, that is, if the prism be placed in the posi tion of minimum deviation.

All these phenomena of refraction by a prism, which are of great importance to the spectroscope, may be verified in a very striking manner by using as an object a piece of wire gauze, placed so that one set of wires is horizontal and the other vertical, and illuminated by a sodium flame placed behind it. If the light pass directly from the gauze to the prism, the focal lines are of course virtual, but they may be easily viewed and their positions identified by means of a telescope which will focus an object at a short distance. For one position of the eye-piece of the telescope the vertical wires are seen distinctly while no horizontal wires are seen; whereas for another position the horizontal wires may be focused, but then the vertical ones are no longer visible unless the prism is in the position of minimum deviation. Between these two positions of the eye-piece is a third, for which a blurred image of the gauze is seen corresponding to the circles of least confusion. The positions of the lines may be determined by ascertaining where an object must be placed, when the prism is removed, so as to be in focus in the telescope for the two positions of the eye-piece corresponding to the two focal lines respectively.

The experiment is, however, much more striking if the focal lines be made real by interposing between the gauze and the prism a convex lens of somewhat long focal length. The vertical and horizontal images may then be viewed by means of an ordinary watchmaker's glass, or, better still, by a telescope eye-piece mounted behind a second gauze with its wires set at $45^{\circ}$ to the horizon. With this arrangement the images corresponding to the two focal lines can be seen very clearly, and their distances from the prism accurately measured. It is very interesting to place the prism first in the position of minimum deviation, and focus the magnifier upon the image of the gauze, showing both horizontal and vertical wires clearly defined; then on gradually turning the prism the vertical lines disappear completely, leaving a set of horizontal bars across the uniform field, thus verifying the first formula cited above.

If however, the eye-piece be drawn back some way, a badlydefined image of the gauze can be obtained corresponding to the circles of least confusion, and, on withdrawing the eye-piece still further, the horizontal line; disappear entirely, while the vertical lines come out sharply defined as a set of vertical bars across a uniform field. As the experiment was arranged here, with a prism of about $9^{\circ}$ and the horizontal focal line about two feet from the prism, the distance between the two images was fully six inches when the prism was turned through an angle of about $15^{\circ}$ from the position of minimum deviation.

The properties of the focal lines formed by a pencil incident 
obliquely upon a lens can be verified in an exactly similar manner. It follows from the formule given in Parkinson's "Optics" (p. IOI) that, with the usual notation-

$$
\frac{u-v_{1}}{u-v_{2}} \cdot \frac{z_{2}}{v_{1}}=\sec ^{2} \phi \text {. }
$$

The verification of this formula by the method of observation described above has been found to be a very useful and satisfactory class experiment.

Cavendish Lalsoratory, Cambridge

W. N. SHAw

\section{UNIVERSTTY AND EDUCATIONAL INTELLIGENCE}

CAmbridgr.-The election of Mr. A. Marshall as Professor of Political Fconomy will be welcomed by all who kncw the value of his work when formerly in residence as Iecturer at St. John's College.

The Senate has sanctioned the recommendation that $700 \%$ be expended on the purchase of microscopes for the biological classes, on which sum interest at 4 per cent. is to be paid, a small terminal charge being made to the students for the use of the microscopes.

The Botanic Garden Syndicate have recommended the increase of the stipend of the Curator of the Botanic Garden from 150 l. to $200 l$. The Syndicate have watched with interest the zeal and skill with which Mr. Iynch has applied himself to the conduct and development of the garden. The improvement during his curatorship has been very considerable, in fact remarkable; and the repulation of the garden among botanists and horticulturists, both at home and abroad, has risen so much that it is now considered to hold a place in England second only to the Royal Gardens at Kew. Sir Josejh Hooker has said that the Garden, under Mr. Lynch's able management, is rapidly rising to eminence as one of the very best in Europe. The Syndicate express their strong approval of the assistance which Mr. Lynch's intelligent appreciation of the requirements of botanical teaching has enabled him to render to the University.

Dr. Gubert, Professor of Rural Economy at the University of Oxford, and the associate of Sir J. B. Lawes in the Rothamsted experimental work, has accepted the post of Honorary Professor of Agricultural Chemistry at the Royal Agricultural College, Circncester, rendered vacant by the death of Dr. Voelcker.

Mr. D'ArCy Wentworth Tilompson, B.A., was on Mon day elected Professor of Biology, University College, Dundee.

\section{SOCIETIES AND ACADEMIES LONDON}

Physical Society, December 13.-Prof. Guthrie, President, in the chair.- The following communications were read:--On the effect of an electrical current on the rate of thinning of a liquirl film, by Profs. A. W. Reinold, F.R.S., and A. W. Riicker, F.R.S., read hy Prof. Reinold. In 1877 the authors communicated to the Royal Society an account of some experiments upon the electrical resistance of liquid films. The results then obtained showed that there was some disturbing influence present, and the authors now find this to be the action of the current upon the film itself. The films cxperimented on were, as in the original experiments, cylindrical and vertical, formed upon two coaxial platinum rings which are the electrodes by which an electric current can enter or leave the film. The mode of formation of these films and the precautions necessary to keep them from gaining or losing moisture by condensation or cvaporation have been already described before the Royal Society (Phil. Trans, 188r, part 2). When such a film, just formed, is left to itself, it shows a set of colours of different orders arranged in horizontal bands ; as it thins under the action of gravity, these bands gradually broaden out, and descend; a black band soon appears at the top, which likewise extends downwards. If a current is now passed downwards through the film, the motion of the colour-bands is accelerated, showing that the effect of the current is to assist gravity in thinning the film; the black band, however, becomes in part or entirely white. This upon examination is found to be due to the following action ; the film is not directly dependent upon the upper ring, but is attached to it by a comparatively thick mass of liquid. The action of the current is to transfer liquid in its own direc- tion, thus, like gravity, thimning the film; the mass of liquid, however, on which the film hangs, by this same action is forced down into the black portion, which consequently becomes white. If the current be passed upwards, the reverse effects occur: the downward motion of the bands is retarded, or, with a strong current, reversed. The explanation is precisely the same as before: the liquid is transferred along the film in the direction of the positive current; it sometimes collects in the form of pendent drops attached to the upper ring; these increase in size, and stream down the sides of the film. Prof. Reinold then formed a planc film between two horizontal wires; the film was illuminated by the lime-light, and its image projected upon a scren ; the motion of the ban's of colour in the direction of the current produccd by fifty Grove's cells was clearly shown.In a discussion which followed upon the transference of matter with the current, Prof. Ayrton described some experiments recently made by Prof. Perry and himself, which showed that certain metals were carried through mercury in the direction of the current. Mr. Boys remarked upon the apparent inertia of the film; the current seemed to requirc time to develop its action, no motion of the colour-rings being visible for some seconds after making the current.-I)r. Stone exhibited a tuning-fork interruptor commutator. This is an instrument for reversing an electric current through a circuit a given number of times per sccond. From the free eud of a spring, kept vibrating in unison with an electrically maintained fork, by an electromagnet in the circuil of the fork acting upon an iron armature attacherl to the spring, project two small aluminium plates, side by side, but insulated by ebonite from the spring and from each other. These are connected by fine wivos, which do not interfere with the vibration of the spring, to siews upon the base of the instrument, to which the poles of a battery are joined. The motion of each plate is arrested upwards and rownwards by aluminium-stops, so that there are four such stops arranged at the corners of a rectangle. They are connected in pairs diagonally, and each pair is in communication with one end of the external circuit. Thus, when the spring is up, the current flows to the aluminium plates, and is transmitted through the circuit in one direction; when the spring is down, it fluws by the lower stops in the opposite direction. The electromotive force is thus reversed in the circuit twice as many times as the fork vibrates per second.-Mr. Lewis Wright exhibited his new oxy-hydrogen lantern microscope. Details of this instrument will shortly be published. Geological, medical, and biological specimens were exhibited upon the screen with great distinctness, the definition being singularly perfect under the highest powers.

Anthropological Institute, December 9.-Prof. Flower, F.R.S., President, in the chair.-The election of Miss Müller was announced.-Sir John Lubbock read a paper on marriage customs and relationships among the Australian aborigines. Many tribes are divided into families "or gentes, and no man may marry a woman of his own gens. For instance, among the Mount Gambier (South Australia) natives every man is a Kumite or a Kroki, every woman a Kumitegor or a Kroligor. No Kumite may marry a Kumitegor, nor a Krolsi a Krokigor. In many cases the divisions are more complex, but the general principle is that no man may marry a woman of the same gens as himself. These divisions often extend through many tribes and over hundreds of miles. But while these restrictions are im. posed on marriage, on the other hand, in one sense, every man is considered as a husband of every woman belonging to the gens with which he is permitted to marry; so that, as Messrs. Fison and Howitt forcibly put it, he may bave rooo miles of wives. But though we may call this marriage, and it is a right which in old times was gencrally, and to a certain extent still is, recognised as perfectly legal and respectable, it cloes not help us to the origin of marriage in our sense. "Communal marriage" (as he had proposerl to call it) was no doubt aboriginal, and founded on natural instincts. But how did the institution of "individual marriage" arise? "Individual marriage" cannot be derived from "communal marriage," because, however much the gentes may be subdividled, the wivcs must remain in common within the gens. Messrs. Fison and Howitt did not, he thought, sufficiently realise the fundamental distinction between these two eustoms. They spoke of both as "marriage," and incleed we had no other word for them. Yet they were radically distinct, and even opposite in their characteristics. Sir John Lubbock had suggested, in his work on the "Origin of Civilisation," that, while in such a state of things no man could 